\title{
Avaliação Ergonômica em Atividades de Colheita Semimecanizada na Caatinga
}

\author{
Giselle Lemos Moreira1*, Joanna Letícia Diniz Mello², Flavio Cipriano de Assis do Carmo², Libânia da Silva Ribeiro², \\ Pedro Nico de Medeiros Neto 2 , Francisco das Chagas Vieira Sales ${ }^{2}$
}

\begin{abstract}
RESUMO: Objetivou-se com esse trabalho realizar uma avaliação da carga de trabalho físico e da postura adotada nas atividades de colheita semimecanizada de espécies invasoras no Horto Florestal da Universidade Federal de Campina Grande, Campus de Patos. A carga de trabalho físico foi avaliada por intermédio do levantamento da frequência cardíaca durante a jornada de trabalho. A avaliação da postura foi obtida por meio de fotografias e filmagens das posturas na execução do trabalho, sendo os dados submetidos para análise no software "Winowas". Os resultados mostraram que as posturas adotadas nas atividades de abate, processamento e empilhamento manual requer medidas corretivas em longo prazo. A operação de abate foi considerada prejudicial, por exigir uma sobrecarga da coluna lombar na maior parte da jornada de trabalho. A análise da carga de trabalho físico indicou que as atividades que exigiram maior carga física de trabalho foram empilhamento e processamento, consideradas como pesada. As demais operações foram classificadas como moderadamente pesada.
\end{abstract}

Palavras-chave: Colheita Florestal, Ergonomia, Postura.

\section{Ergonomic Assessment in Semi-Mechanized Harvesting Activities in the Caatinga}

\begin{abstract}
The objective of this work was to carry out an evaluation of the physical workload and posture adopted in the activities of semi-mechanized harvesting of invasive species in the Horto Florestal of the Federal University of Campina Grande, Campus de Patos. The physical workload was assessed by surveying the heart rate during the workday. The posture evaluation was obtained by means of photographs and video of the postures in the execution of the work, and the data were submitted for analysis in the "Winowas" software. The results showed that the postures adopted in the activities of slaughter, processing and manual stacking require long-term corrective measures. The slaughter operation was considered harmful, as it requires an overload of the lumbar spine for most of the workday. The analysis of the physical workload indicated that the activities that required greater physical workload were stacking and processing, considered as heavy. The other operations were classified as moderately heavy.
\end{abstract}

Keywords: Forest harvesting, Ergonomics, Posture.

\section{INTRODUÇÃO}

O setor florestal, vem passando por uma significativa expansão, sendo importante buscar o aperfeiçoamento das técnicas e operações florestais para melhoria da saúde e a segurança no trabalho e sustentabilidade econômica, ambiental e social (GONÇALVES, 2014).

A palavra ergonomia é de origem latim e significa ciência do trabalho. Os estudiosos em ergonomia são pesquisadores preocupados com a adaptação do sistema de trabalho ao ser humano. Nesta ciência, o trabalhador é o principal elemento do sistema de produção e a execução das suas atividades preservando sua saúde, segurança, bem-estar, conforto e satisfação devem ser as principais metas das pesquisas.

Para Iida (2016), a ergonomia é o conjunto de conhecimentos a respeito do desempenho do ser humano em suas atividades, a fim de aplicá-los à realização das tarefas, aos instrumentos, às máquinas e aos sistemas de produção. Essa ciência apoia-se em dados sistemáticos, fazendo uso de métodos científicos para se chegar à adaptação da atividade à pessoa que a realiza, ou seja, visa sempre à melhoria das condições de segurança, saúde, conforto e eficiência do ser humano.

As atividades de colheita florestal, em geral, necessitam de um número expressivo de trabalhadores, sendo algumas operações de elevada exigência física, que podem originar inúmeras doenças. Tais atividades exigem tratamento médico e uma avaliação completa dos postos de trabalho, para que haja mudança no ambiente ou no método de trabalho. Na busca dessas soluções, as avaliações ergonômicas podem ser o elemento essencial na tomada de decisões (BERUDE et al., 2015).

Segundo Lopes e Fiedler (2010), a ergonomia tem como objetivos a segurança, satisfação e bem-estar

Recebido em 11/03/2019; Aceito para publicação em 10/07/2021

1Universidade Federal Rural de Pernambuco

${ }^{2}$ Universidade Federal de Campina Grande

* Email: gisellemoreira28@gmail.com 
dos trabalhadores no seu relacionamento com os sistemas produtivos, pois utiliza os conhecimentos científicos de diversas áreas como a engenharia, medicina, física e biologia para aplicar na adaptação do local de trabalho e ambiente às características e necessidades do trabalhador.

Dentre as atividades de colheita florestal, os principais fatores ergonômicos são o manuseio de cargas, os biomecânicos, envolvendo as posturas, as forças aplicadas, a carga de trabalho físico e os movimentos repetitivos, que têm influência direta sobre a saúde do trabalhador e, consequentemente, sobre a eficiência da operação.

Diante do exposto, o objetivo deste trabalho foi diagnosticar e avaliar as condições ergonômicas do trabalho nas atividades de corte semimecanizado de espécies invasoras do Horto Florestal da Universidade Federal de Campina Grande, Campus de Patos, no que se refere a biomecânica do trabalho de colheita florestal e as posturas adotadas durante as atividades de corte da madeira. Além disso, visou-se também fornecer subsídios para atuar na melhoria das condições de saúde, segurança, bem-estar, satisfação e qualidade de vida dos trabalhadores.

\section{MATERIAL E MÉTODOS \\ Caracterização da área de estudo}

Os dados da pesquisa foram coletados em novembro/2019 e fevereiro/2020, em áreas com espécies invasoras, na área do Horto Florestal do CSTR/UFCG, Campus Patos, que corresponde a uma área de 3,8 ha. Localizado nas coordenadas geográficas $7^{\circ} 13$ '08'S, 35 54 '05' W e altitude 250 metros. As atividades foram realizadas com um operador de motosserra, executando as operações de abate, processamento, carregamento e empilhamento dos indivíduos, bem como o abastecimento da motosserra. O trabalhador possuía idade de 49 anos, e a motosserra utilizada foi da marca, com peso médio de 7,0 $\mathrm{kg}$ abastecido. (Figura 1).

Figura 1. Operador realizando o corte espécies no Horto Florestal do CSTR/UFCG.

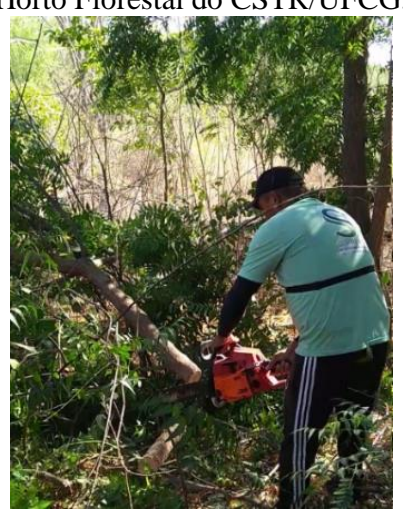

O clima da área em estudo é do tipo BSh, quente e seco, com temperaturas médias anuais variando de $27^{\circ}$ a $38^{\circ}$, segundo a classificação de Köppen (PEEL et al., 2007) e pluviosidade média anual inferior a 800 $\mathrm{mm}$ com chuvas irregulares e umidade relativa do ar média de 65,9 (AESA, 2006).

\section{Análise da carga física de trabalho}

A avaliação da carga de trabalho físico foi realizada por meio da determinação da carga cardiovascular durante a jornada de trabalho. Os dados foram coletados utilizando um monitor de frequência cardíaca, constituído de três partes: um receptor digital de pulso, uma correia elástica e um transmissor com eletrodos.

O sistema de coleta de dados foi fixado na altura do peito do trabalhador no início da jornada de trabalho e retirado para almoço e colocado novamente até o final da jornada de trabalho. Sendo os valores captados, manualmente, em intervalos de cinco segundos. Simultaneamente, foi feito um estudo de tempos e movimentos para registrar a atividade que estava sendo executada, de acordo com a frequência cardíaca obtida.

Com essas análises, foi possível calcular a carga física de trabalho do motosserrista, obter a carga cardiovascular no trabalho, que representa a porcentagem da frequência cardíaca em relação à frequência cardíaca máxima, tolerável para uma jornada de trabalho de 8 horas diárias. O valor dessa carga foi calculado pela equação 1 proposta por Apud (1997):

$$
\mathrm{CCV}=(\mathrm{FTC}-\mathrm{FCR}) /(\mathrm{FCM}-\mathrm{FCR}) * 100
$$

Em que:

$\mathrm{CCV}=$ carga cardiovascular, em \%;

$\mathrm{FCT}=$ frequência cardiovascular de trabalho, em bpm (batimentos por minuto);

$\mathrm{FCR}=$ frequência cardíaca em repouso;

$\mathrm{FCM}=$ frequência cardíaca máxima (220 - idade).

A frequência cardíaca limite (FCL) em bpm, para carga cardiovascular de $40 \%$, foi obtida utilizando-se a seguinte equação proposta por Apud (1997): 


$$
\mathrm{FCL}=0,40 *(\mathrm{FCM}-\mathrm{FCR})+\mathrm{FCR}
$$

Para atividades que excederam a carga cardiovascular de $40 \%$ (acima da frequência cardíaca limite), visando reorganizar o trabalho, foi determinado o tempo de repouso (pausa) necessário, segundo Apud (1997), pela equação 3:
$\operatorname{Tr}=(\mathrm{Ht} *(\mathrm{FCT}-\mathrm{FCL})) /(\mathrm{FCT}-\mathrm{FCR})$

Em que:Tr = tempo de repouso, descanso ou pausa, em minutos;

$\mathrm{Ht}=$ duração do trabalho em minutos.

Tabela 1. Classificação da atividade por frequência cardíaca média de trabalho.

\begin{tabular}{lc}
\hline Carga Física de Trabalho & Frequência Cardíaca (em bpm) \\
\hline Muito leve & $<75$ \\
Leve & $75-100$ \\
Moderadamente pesada & $100-125$ \\
Pesada & $125-150$ \\
Pesadíssima & $150-175$ \\
Extremamente pesada & $>175$ \\
\hline
\end{tabular}

Fonte: Apud (1997), citado por Vosniak et al (2010).

\section{Análise das posturas adotadas pelos operadores de motosserra}

A análise de posturas no trabalho foi feita com o uso do método OWAS que foi desenvolvido na Finlândia para analisar as posturas de trabalho na indústria de aço. No método é realizado filmagens dos trabalhadores utilizando-se uma câmera filmadora, com monitoramento dos movimentos e posições de perfil em cada atividade executada. Para análise das filmagens, as imagens foram congeladas e as posições verificadas.

O software utilizado para avaliação foi o WinOWAS, sendo coletados dados de posturas a cada intervalo de cinco segundos, verificando-se, assim, a posição mais frequente relativa a cada operação. Este também auxiliará na análise e avaliação das posturas nas atividades predeterminadas, caracterizando a postura das costas, braços, pernas e ainda o esforço realizado durante a execução da tarefa.

O manual WinOWAS define 72 posturas típicas que resultam de diferentes combinações das seguintes posições: Dorso -4 posições típicas; Braços -3 posições típicas; Pernas - 7 posições típicas. Aliado a isto, o peso manuseado é mensurado e utilizado na base de dados do software, conforme apresentado na Tabela 2.

Tabela 2. Determinação de postura de acordo com o método OWAS.

\begin{tabular}{llll}
\hline \multicolumn{2}{l}{ Costas } & \multicolumn{2}{l}{ Braços } \\
\hline 1 & Ereta & 1 & Ambos abaixo do nível do ombro; \\
2 & Inclinada & 2 & Um acima do nível do ombro; \\
3 & Ereta e torcida & 3 & Ambos acima do nível do ombro. \\
4 & Inclinada e torcida & & \\
\hline & Pernas & Peso ou força requerida: \\
\hline 1 & Sentado, com as pernas abaixo do nível das nádegas; & Carga menor ou igual a $10 \mathrm{Kg} ;$ \\
2 & Em pé, exercendo força em ambas as pernas; & Carga maior que 10 Kg e menor que 20 Kg; \\
3 & Em pé, exercendo força em uma única perna; & 3 & Carga maior que 20 Kg. \\
4 & Em pé, ou abaixado em ambos os pés, com as pernas flexionadas; & & \\
5 & Em pé, ou abaixado com um pé e perna articulada; & & \\
6 & Ajoelhado com um ou ambos os joelhos; & & \\
7 & Andando ou movimentando. & & \\
\hline
\end{tabular}

Fonte: Adaptado do manual do OWAS (1990).

Segundo Iida (2016), o mesmo trabalhador, quando observado de manhã e à tarde, conserva $86 \%$ das posturas registradas e, diferentes trabalhadores, executando a mesma tarefa, usavam, em média, $69 \%$ de posturas semelhantes. Portanto, concluiu-se que o método de registro apresentava uma consistência razoável. Após a definição das posturas padrões, definiram-se os mecanismos de ação e a necessidade de correção das posturas adotadas, de acordo com a Tabela 3, conforme o modelo OWAS: 
Tabela 2. Categorias de ação de acordo com o software OWAS.

Classe 1 - Não são necessárias medidas corretivas;

Classe 2 - São necessárias correções em um futuro próximo;

Classe 3 - São necessárias correções tão logo quanto possível;

Classe 4 - São necessárias correções imediatas.

Fonte: Adaptado do manual do OWAS (1990).

\section{RESULTADOS E DISCUSSÃO}

$\mathrm{Na}$ análise dos dados de posturas, obtiveram-se os resultados para cada atividade, a partir dos códigos gerados foi realizada a classificação, visando identificar as posturas padrões, porcentagem de cada posicionamento e categoria de ação para as atividades. Os resultados estão apresentados por atividade, conforme Tabela 3.

Tabela 3. Atividades, posturas padrões, porcentagem de cada posicionamento e categoria de ação nas atividades.

\begin{tabular}{|c|c|c|c|c|}
\hline , & POSTURA & REPETIÇÕES & $\%$ & CATEGORIA \\
\hline ABATE & $\begin{array}{l}2-1-4-2 \\
2-1-5-2 \\
3-1-3-2 \\
4-1-3-2 \\
4-1-2-2 \\
4-1-4-2 \\
\text { Total }\end{array}$ & $\begin{array}{l}1 \\
1 \\
1 \\
1 \\
2 \\
3 \\
9\end{array}$ & $\begin{array}{l}11,11 \\
11,11 \\
11,11 \\
11,11 \\
22,22 \\
33,33 \\
100,00\end{array}$ & $\begin{array}{l}3 \\
3 \\
1 \\
2 \\
2 \\
4\end{array}$ \\
\hline PROCESSAMENTO & $\begin{array}{l}3-1-2-2 \\
2-1-2-2 \\
1-1-3-2 \\
4-1-3-2 \\
4-1-2-2 \\
2-1-3-2 \\
2-1-7-2 \\
3-2-4-3 \\
2-1-5-2 \\
3-2-3-2 \\
2-2-3-2 \\
4-2-3-2 \\
1-1-2-1 \\
\text { Total }\end{array}$ & $\begin{array}{l}3 \\
9 \\
1 \\
3 \\
9 \\
8 \\
1 \\
1 \\
1 \\
1 \\
1 \\
1 \\
1 \\
40\end{array}$ & $\begin{array}{l}7,50 \\
22,50 \\
2,50 \\
7,50 \\
22,50 \\
20,00 \\
2,50 \\
2,50 \\
2,50 \\
2,50 \\
2,50 \\
2,50 \\
2,50 \\
100,00\end{array}$ & $\begin{array}{l}1 \\
2 \\
1 \\
2 \\
2 \\
2 \\
3 \\
4 \\
3 \\
1 \\
3 \\
3 \\
1\end{array}$ \\
\hline 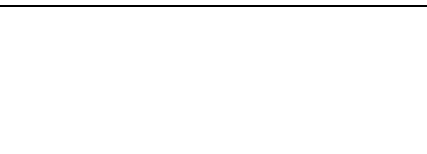 & $\begin{array}{l}4-2-4-2 \\
2-1-7-2 \\
1-3-7-2 \\
2-1-7-2\end{array}$ & $\begin{array}{l}1 \\
1 \\
1 \\
2\end{array}$ & $\begin{array}{l}9,09 \\
9,09 \\
9,09 \\
18,18\end{array}$ & $\begin{array}{l}4 \\
3 \\
1 \\
3\end{array}$ \\
\hline CARREGAMENTO & $\begin{array}{l}2-2-5-3 \\
1-1-7-3 \\
2-1-3-2 \\
4-1-4-1 \\
\text { Total }\end{array}$ & $\begin{array}{l}1 \\
3 \\
1 \\
1 \\
11\end{array}$ & $\begin{array}{l}9,09 \\
27,27 \\
9,09 \\
9,09 \\
100,00\end{array}$ & $\begin{array}{l}4 \\
1 \\
2 \\
4\end{array}$ \\
\hline EMPILHAMENTO MANUAL & $\begin{array}{l}2-2-3-1 \\
2-1-3-2 \\
\text { Total }\end{array}$ & $\begin{array}{l}1 \\
4 \\
5\end{array}$ & $\begin{array}{l}20,00 \\
80,00 \\
100,00\end{array}$ & $\begin{array}{l}2 \\
2\end{array}$ \\
\hline
\end{tabular}

As posturas 4/1/4/2 (costas inclinadas e torcida, ambos os braços abaixo do nível do ombro, de pé ou agachado com ambos os joelhos flexionados e carga entre 10 e $20 \mathrm{Kg}$ ) e 4/1/2/2 (costas inclinadas e torcida, ambos os braços abaixo do nível do ombro, de pé com ambas as pernas esticadas e carga entre 10 e $20 \mathrm{Kg}$ ) foram mais repetidas na atividade de abate, somando 55,56\% de todas as posturas adotadas.

Os posicionamentos com maiores números de repetições no processamento foram os $2 / 1 / 2 / 2$, sendo, costas inclinadas, ambos os braços abaixo do nível do ombro, de pé com ambas as pernas esticadas e carga entre 10 e $20 \mathrm{Kg}$ e 4/1/2/2 sendo, costas inclinadas e torcida, ambos os braços abaixo do nível do ombro, de pé com ambas as pernas esticadas e carga entre 10 e $20 \mathrm{Kg}$. As posições foram repetidas 18 vezes em um total de 40 , equivalendo a $45 \%$ de todas as posturas adotadas no trabalho. Pode-se observar também a postura 2/1/3/2 com grande percentual, com $20 \%$ do total amostrado. 
Observa-se que na operação de carregamento manual o posicionamento com maior número de repetições foi o 1/1/7/3, ou seja, costas eretas, ambos os braços abaixo do nível do ombro, andando ou se movimentando e carga maior que $20 \mathrm{Kg}$. No tombamento manual, verificou-se a presença de muitas posturas distintas, sendo uma atividade de posicionamento heterogêneo. No entanto, as posturas 2/1/7/2, 4/1/4/1 e, juntamente com a postura padrão $2 / 1 / 3 / 2$, representam uma grande parcela das posturas adotadas em todo o trabalho.

No empilhamento manual, as posturas padrões foram a 2/1/3/2 (costas inclinadas, ambos os braços abaixo do nível do ombro, de pé, com o peso de uma das pernas esticadas e carga entre 10 e $20 \mathrm{Kg}$ ) e a 2/2/3/1, ou seja, costas inclinadas, um braço no nível ou acima dos ombros, de pé, com o peso de uma das pernas esticadas e carga menor que $10 \mathrm{Kg}$. Juntas, repetiram-se durante todo $\mathrm{o}$ processo de empilhamento. Segundo o sistema OWAS, a postura
2/1/3/2, de classe 2, necessita de correções, entretanto, a postura $2 / 2 / 3 / 1$, de classe 4 , necessita de correções tão logo quanto possível.

Verifica-se que a posição mais utilizada durante todas as etapas de colheita foi a 2/1/3/2, costas inclinadas, ambos os braços abaixo do nível do ombro, de pé, com o peso de uma das pernas esticadas e carga entre 10 e $20 \mathrm{Kg}$, posicionamento que exige correções de acordo com a classe 2 do modelo OWAS.

Pode-se observar na Tabela 4 que nas atividades de processamento e empilhamento manual a classe de ação de acordo com o modelo OWAS foi a classe 2, ou seja, são necessárias correções em um futuro próximo. No carregamento, a classe de ação foi a classe 1, não sendo necessário efetuar medidas corretivas. Para o abate, são necessárias correções imediatas, enquadrando-se na classe 4 de mecanismos de ação.

Tabela 4. Posições padrão de cada atividade e respectiva categoria de ação de acordo com o modelo OWAS.

\begin{tabular}{lll}
\hline Atividade & Posição padrão & Categoria de ação de acordo com o modelo OWAS \\
\hline Abate & $4-1-4-2$ & Classe 4 - São necessárias correções imediatas \\
Processamento & $2-1-2-2$ & Classe 2 - São necessárias correções em um futuro próximo \\
Carregamento & $1-1-7-3$ & Classe 1 - Não são necessárias medidas corretivas \\
Empilhamento Manual & $2-1-3-2$ & Classe 2 - São necessárias correções em um futuro próximo \\
\hline
\end{tabular}

Na Tabela 5, observa-se que, de todas as atividades avaliadas, foram registradas 7 posturas na classe 1,9 posturas na classe 2,8 na classe 3 e 5 na classe 4. A classe que obteve maior número de repetições foi a classe $2(31,03 \%)$. Vieira et al. (2015) também encontrou maior número de repetição das posturas nas atividades de corte semimecanizado na classe 2 .

Tabela 5. Valores totais de repetição e porcentagem para cada classe.

\begin{tabular}{lllll}
\hline & Classe 1 & Classe 2 & Classe 3 & Classe 4 \\
\hline Repetição & 7 & 9 & 8 & 5 \\
$\%$ & 24,14 & 31,03 & 27,59 & 17,29 \\
\hline
\end{tabular}

As frequências cardíacas de repouso (FCR), em operação (FCT), máxima (FCM) e limite (FCL), a carga cardiovascular $(\mathrm{CCV})$, o tempo de repouso $(\mathrm{Tr})$
Para a realização das atividades é fundamental adotar bom posicionamento, evitando manter-se posturas prolongadas, visto que a mesma posição poderá prejudicar os músculos e as articulações, resultando em tensões localizadas com maior exigência física (Dul; Weerdmeester, 2012). e a classificação do trabalho durante a jornada de trabalho são apresentadas na Tabela 6 .

Tabela 6. Carga física de trabalho exigida nas atividades estudadas.

\begin{tabular}{cccccccc}
\hline Atividade & $\begin{array}{c}\text { FCR } \\
(\mathbf{b m p})\end{array}$ & $\begin{array}{c}\text { FCT } \\
(\mathbf{b p m})\end{array}$ & $\begin{array}{c}\text { FCM } \\
(\mathbf{b p m})\end{array}$ & $\begin{array}{c}\text { FCL } \\
(\mathbf{b p m})\end{array}$ & $\begin{array}{c}\text { CCV } \\
(\mathbf{\%})\end{array}$ & Tr $(\mathbf{m i n} / \mathbf{h r})$ & $\begin{array}{c}\text { Classificação da } \\
\text { atividade }\end{array}$ \\
\hline Abate & 102 & 123,56 & 171 & 129,6 & 31,24 & - & Moderadamente pesada
\end{tabular}




\begin{tabular}{ccccccc}
\hline Processamento & 102 & 126,27 & 129,6 & 35,17 & - & Pesada \\
Extração sem carga & 103 & 120,78 & 130,2 & 26,14 & - & Moderadamente pesada \\
$\begin{array}{c}\text { Extração com carga } \\
\text { Empilhamento } \\
\quad \text { Manual }\end{array}$ & 103 & 123,08 & 130,2 & 29,52 & - & Moderadamente pesada \\
\hline
\end{tabular}

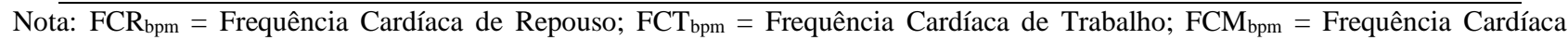
Máxima; $\mathrm{CCV}_{\%}=$ Carga Cardiovascular; $\mathrm{FCL}_{\mathrm{bpm}}=$ Frequência Cardíaca Limite; $\operatorname{Tr}_{\mathrm{min} / \mathrm{h}}=$ Tempo de Repouso.

As atividades de maior carga física na colheita semimecanizada Horto Florestal da UFCG, Campus Patos foram as atividades de empilhamento e processamento, classificadas como pesadas, com frequência cardíaca de trabalho de 128,25 bpm e 126,27 bpm, e carga cardiovascular de $38,04 \%$ e 35,17. As atividades de menores frequências cardíacas de trabalho foram de abate, extração com carga e extração com carga, classificadas como moderadamente pesadas, com frequência cardíaca de trabalho de 123,56 bpm, 123,08 bpm, 120,78 bpm, consecutivamente.

O cálculo do tempo de repouso para as atividades não foi necessário. Visto que nenhuma atividade exigiu esforço de modo que a carga cardiovascular ultrapassasse o limite de $40 \%$ da frequência cardíaca de trabalho. Porém, é importante estabelecer o incentivo a pausas para descanso e relaxamento muscular, visando evitar danos à saúde do trabalhador.

\section{CONCLUSÕES}

As posturas adotadas nas atividades de processamento e empilhamento foram inadequadas e necessitam de correções no futuro.

A atividade de abate foi mais crítica e necessita de correções imediatas, já que o trabalhador permanecia com as costas curvadas na maior parte da jornada de trabalho, exigindo uma sobrecarga da coluna lombar

$\mathrm{Na}$ operação de carregamento não há a necessidade de medidas corretivas com relação às posturas, sendo estas consideradas satisfatórias.

As atividades que exigiram maior carga física de trabalho foram empilhamento e processamento, consideradas como pesada. As demais operações foram classificadas como moderadamente pesada.

\section{REFERÊNCIAS}

AESA. Secretaria de Estado da Ciência e Tecnologia e do Meio Ambiente - SECTMA. Agência Executiva de Gestão de Águas do Estado da Paraíba - AESA. PERH-PB: Plano Estadual de Recursos Hídricos. 2006. Disponível em: <http://www.aesa.pb.gov.br/aesawebsite/documentos/plan o-estadual/resumo-estendido/>. Acesso em: 07 fev. 2020.

APUD, E. Guide-lines on ergonomics study in forestry. Genebra: ILO, 241p. 1997.
BERUDE， L.C.; FIEDLER， N. C.; GONCALVES， S. B.; CARMO, F. C. A.; Guerra, L.L. Análise de posturas no combate a incêndios em florestas plantadas. Revista Científica Eletrônica de Engenharia Florestal, Garça, v. 26, p. 1-10, 2015.

DUL, J.; WEERDMEESTER, B. Ergonomia prática. 3. ed. São Paulo: Blucher, 2012. 163 p.

FIEDLER, N. C.; ALEXANDRE FILHO, P. C. R. T.; GONÇALVES, S. B.; CARMO, F. C. A.; LACHINI, E. Análise Biomecânica da Carga e Descarga Manual de Madeira de Eucalipto. Revista Nativa, Sinop, v. 3, p. 179184, 2015.

GONÇALVES, S. B. Avaliação da qualidade da subsolagem em diferentes condições de solo. 2014. 68f. Dissertação (Mestrado em Ciências Florestais) Universidade Estadual do Centro-Oeste, Irati, 2014.

IIDA, I. Ergonomia: projeto e produção. São Paulo: Edgard Blucher, $3^{\mathrm{a}}$ Edição, 2016. 850 p.

LOPES, E. S.; FIEDLER, N. C. Ergonomia e segurança do Trabalho aplicado no Setor Florestal. In: X Semana de Estudos Florestais e I Seminário de Atualização Florestal. Irati-Paraná. Anais... Paraná: Unicentro, 2010.

FIOH. OWAS. Manual Ovako Working Analysing System. Helsinki: Finnish Institute of Occupational Health, 1990. 503p.

PEEL, M. C.; FINLAYSON, B. L.; MCMAHON, T. A. Updated world map of the Köppen-Geiger climate classification. Hydrology Earth Syst Science, v. 11, n. 5, p. 1633-1644, 2007.

VIEIRA， F.; FIEDLER， N.; LOUSADA， J. L.; GONÇALVES, S.; CHICHORRO, J.; CARMO, F. Posturas e Carga Física de Trabalho na Colheita Florestal Semimecanizada. Silva Lusitana, v. 23, p. 61-78, 2015.

VOSNIAK, J.; LOPES, E. S.; FIEDLER, N. C.; ALVES, R. T.; VENANCIO, D. L. Carga de trabalho físico e posturas na atividade de coveamento semimecanizado em plantios florestais. Revista Scientia Forestalis (IPEF), v. 38, p. 589-598, 2011.

WATERS, T. R.; ANDERSON, V. P.; GARG, A. Applications manual for the revised NIOSH lifting equation. Cincinnati: U. S. Department of Health Human Services, 1994. 119p. 